\title{
Molecular Variability Among Isolates of Prunus Necrotic Ringspot Virus from Different Prunus spp.
}

\author{
F. Aparicio, A. Myrta, B. Di Terlizzi, and V. Pallás
}

First and fourth authors: Departamento de Mejora y Patología Vegetal, CEBAS-CSIC, Apdo. Correos 4195, Murcia 30080 Spain; and second and third authors: Istituto Agronomico Mediterraneo, Via Ceglie 9, 70010 Valenzano, Bari, Italy. Accepted for publication 21 July 1999.

\begin{abstract}
Aparicio, F., Myrta, A., Di Terlizzi, B., and Pallás, V. 1999. Molecular variability among isolates of Prunus necrotic ringspot virus from different Prunus spp. Phytopathology 89:991-999.

Viral sequences amplified by polymerase chain reaction from 25 isolates of Prunus necrotic ringspot virus (PNRSV), varying in the symptomatology they cause in six different Prunus spp., were analyzed for restriction fragment polymorphisms. Most of the isolates could be discriminated by using a combination of three different restriction enzymes. The nucleotide sequences of the RNA 4 of 15 of these isolates were determined. Sequence comparisons and phylogenetic analyses of the RNA 4 and coat proteins (CPs) revealed that all of the isolates clustered into three different

groups, represented by three previously sequenced PNRSV isolates: PV32, PE5, and PV96. The PE5-type group was characterized by a $5^{\prime}$ untranslated region that was clearly different from that of the other two groups. The PV32-type group was characterized by an extra hexanucleotide consisting of a duplication of the six immediately preceding nucleotides. Although most of the variability was observed in the first third of the $\mathrm{CP}$, the amino acid residues in this region, which were previously thought to be functionally important in the replication cycle of the virus, were strictly conserved. No clear correlation with the type of symptom or host specificity could be observed. The validity of this grouping was confirmed when other isolates recently characterized by other authors were included in these analyses.
\end{abstract}

Prunus necrotic ringspot virus (PNRSV) is responsible for economically important diseases in most cultivated Prunus spp. throughout the world (28). Many variants have been described covering a wide range of biological diversity $(3,5,12)$. Some isolates do not induce symptoms, whereas others produce characteristic necrotic spots and shot holes in young leaves. The existence of clearly different "pathotypes" has been well described in sweet cherry trees, in which isolates could be classified as M or R depending on whether they produced mild mottle or rugose mosaic symptoms, respectively $(5,12)$. Moreover, isolates from this host can be grouped into three different serotypes ( $\mathrm{CH} 3, \mathrm{CH} 9$, and $\mathrm{CH} 30)$ (13). Recently, sequence comparisons among three mild and three rugose isolates belonging to the $\mathrm{CH} 9$ serotype revealed that single nucleotide and amino acid differences in both the movement protein (MP) and the coat protein (CP) correlated well with serological relationships and symptom type (9). Unfortunately, this correlation could not be observed when CH30 serotype isolates were compared. On the other hand, Scott et al. (25) recently showed that the CPs and putative MPs of five PNRSV isolates are extensively conserved irrespective of their host species or geographic origins. More importantly, the authors (25) were unable to associate any of the changes observed with the symptoms caused by these isolates in cucumber or with the range of host species that they infect, thus reflecting that the situation could be much more complicated than that in sweet cherry trees.

PNRSV is a positive-sense RNA plant virus with a tripartite genome that belongs to the genus Ilarvirus (19). Ilarvirus spp. have the same genomic organization, encoding functionally similar translation products, as members of the genera Bromovirus, $\mathrm{Cu}$ cumovirus, and Alfamovirus, all of which belong to the family Bromoviridae (4). RNAs 1 and 2 of viruses in the family Bromoviridae encode the replicase proteins $\mathrm{P} 1$ and $\mathrm{P} 2$, respectively. RNA 3 is bicistronic and encodes the MP (or P3) and the CP. CP syn-

Corresponding author: V. Pallás; E-mail address: vpallas@ natura.cebas.csic.es

Publication no. P-1999-0910-01R

(c) 1999 The American Phytopathological Society thesis occurs via a subgenomic monocistronic mRNA (RNA 4). Studies of evolutionary relationships, considering first RNA 3 (22) and later RNAs 1 and $2(17,24)$, led to the proposal that alfalfa mosaic virus (AMV) should be considered a true Ilarvirus sp. instead of forming a distinct genus. Accordingly, Sánchez-Navarro et al. (23) showed that the replacement of the MP and CP genes of AMV by the corresponding genes of PNRSV resulted in basic competence for encapsidation and replication in protoplasts and for a low level of cell-to-cell movement in tobacco plants transformed with the replicase proteins.

The relative molecular masses of the CPs of some PNRSV isolates vary within a range of about 27 to $29 \mathrm{kDa}$ (5). Moreover, it has been recently demonstrated that there are differences in the electrophoretic mobility of the RNA 4 transcripts synthesized from the corresponding polymerase chain reaction (PCR) products from six different PNRSV isolates (18). As mentioned above, there are few data about the possible correlation of this heterogeneity and biological properties for PNRSV isolates and for Ilarvirus spp. in general. Only in the case of AMV, a putative member of the Ilarvirus genus, has the CP gene been shown to play a key role in symptom determination (14). To increase knowledge of the molecular variability among PNRSV isolates and in an attempt to correlate this variability with their biological diversity, we determined the primary structure of the RNA 4 of 15 PNRSV isolates that differ in symptom expression and originate from six different Prunus hosts and four different countries.

\section{MATERIALS AND METHODS}

Plant material and RNA extraction. Twenty-five PNRSV isolates from different Prunus hosts and geographical locations were either obtained from a collection kept at the Istituto Agronomico Mediterraneo (Bari, Italy) or collected from orchards in other countries (Table 1). Total nucleic acid was extracted from $0.5 \mathrm{~g}$ of fresh leaf tissue for each isolate as described previously (20). Samples were analyzed for the presence of the virus by nonisotopic molecular hybridization as described (15). 
cDNA synthesis and PCR amplification. First-strand cDNA synthesis was carried out in a $20-\mu$ l reaction containing $50 \mathrm{mM}$ Tris- $\mathrm{HCl}, \mathrm{pH} 8.3 ; 50 \mathrm{mM} \mathrm{KCl} ; 10 \mathrm{mM} \mathrm{MgCl}$; $10 \mathrm{mM}$ dithiothreitol; $0.5 \mathrm{mM}$ spermidine; $1 \mathrm{mM}$ of each dNTP; $40 \mathrm{U}$ of ribonuclease inhibitor (Amersham International, Cleveland, $\mathrm{OH}$ ); $8 \mathrm{U}$ of AMV-reverse transcriptase (RT) (Promega Corp., Madison, WI); and 100 pmol of antisense primer VP33 (5'-CCGGCTGCAGCTTCCCTAACGGGC-3'). The 3' 15 nucleotides (nt) of the primer are complementary to the $3^{\prime}$ terminus of PNRSV RNA 4 (22) and are preceded by the restriction site PstI (underlined). PCR amplifications were made using primer VP33 and the sense primer VPC (5'-CTTGCCATGGTTTGCCGAATTTGC-3', which contains a sequence identical to nt 1,102 to 1,119 and a $N c o$ I site, underlined). For cloning and sequencing purposes, the sense primer used was VP56 (5'-GTTAACGGATCCGTTTTTCTTTTCTTTCTTCCG-3' containing the first $21 \mathrm{nt}$ of RNA 4, a BamHI site [underlined] and six additional unrelated residues at its $5^{\prime}$ end). For the P4090 and C7140 isolates (Table 1), primer VP67 (5'-GTACGGATCCTATTTTATTCCCGATTGC-3', identical to nt 730 to 751 of RNA 3, and containing a BamHI site [underlined]) (Fig. 1A) was used. Five microliters of the reverse-transcription products, $10 \mu \mathrm{l}$ of $10 \times$ buffer $\left(166 \mathrm{mM}\left(\mathrm{NH}_{4}\right)_{2} \mathrm{SO}_{4}, 670 \mathrm{mM}\right.$ Tris- $\mathrm{HCl}, \mathrm{pH} 8.8$, and $0.1 \%$ Tween 20), $3 \mathrm{mM} \mathrm{MgCl}_{2}, 0.2 \mathrm{mM}$ of each dNTP, and $60 \mathrm{pmol}$ of each primer were mixed in a total volume of $100 \mu \mathrm{l}$ for the PCR reactions. Prior to thermal cycling, $1 \mathrm{U}$ of Ecotaq DNA polymerase (Ecogen SRL, London) for restriction fragment length polymorphism (RFLP) analyses or Ecozyme DNA polymerase (Ecogen SRL) for sequencing purposes was added and the 100- $\mu$ l samples overlaid with mineral oil (Sigma Chemical Co., St Louis). PCR was carried out in a Perkin-Elmer 2400 thermal cycler (PerkinElmer Corp., Norwalk, CT) programmed for one cycle at $94^{\circ} \mathrm{C}$ for $2 \mathrm{~min}$, followed by 30 cycles of $94^{\circ} \mathrm{C}$ for $45 \mathrm{~s}, 51^{\circ} \mathrm{C}$ for $45 \mathrm{~s}$, and $72^{\circ} \mathrm{C}$ for $1 \mathrm{~min}$, finishing with an extension at $72^{\circ} \mathrm{C}$ for $5 \mathrm{~min}$. Amplified products (5 $\mu \mathrm{l}$ each) were electrophoresed in $1 \%$ agarose gels in $40 \mathrm{mM}$ Tris-acetate and $1 \mathrm{mM}$ EDTA, $\mathrm{pH}$ 8.0 (TAE), and stained with ethidium bromide to confirm the expected size of the PCR products. A total of $15 \mu$ of the PCR products generated was directly digested with $10 \mathrm{U}$ of EcoRI, RsaI, and TaqI (Boeh- ringer $\mathrm{GmbH}$, Mannheim, Germany) and adjusted to a final volume of $20 \mu \mathrm{l}$ with the corresponding buffer. The mixtures were incubated for $4 \mathrm{~h}$ at $37^{\circ} \mathrm{C}$, except that containing TaqI, which was incubated at $65^{\circ} \mathrm{C}$. DNA fragments were separated by electrophoresis in $10 \%$ polyacrylamide gel for $E c o$ RI and $R s a \mathrm{I}$ and $15 \%$ polyacrylamide gel for TaqI, using TAE buffer. The gels were stained in ethidium bromide and photographed using Polaroid film and an orange filter.

The restriction fragments were identified by position in the gel, and the presence or absence ( 1 or 0 , respectively) of each was recorded in a restrictotype matrix to obtain a clustering of the isolates using the RESTML program of the PHYLIP 3.5c package (6).

Cloning, nucleotide sequencing, and sequence comparisons. PCR products obtained with the pairs of primers VP33-VP56 and VP33-VP67 (Fig. 1A) were extracted from 1\% agarose gels using USBioclean (Amersham International), cloned into the BamHIPstI cut pUC18 vector, and transformed into Escherichia coli DH5 $\alpha$ cells. For all isolates, positive clones were identified by restriction analysis and sequenced in both orientations by using universal and specific internal primers with an automated DNA sequencer (ABI PRISM 377; Perkin-Elmer Corp.). The isolate sequences were named using an eight-letter code. The first three letters correspond to the source of the isolate, followed by two letters indicative of the country, and the last three letters indicating the cultivar (e.g., the first Italian PNRSV isolate obtained from apricot cv. Napoletana would be named AprIt.nap1).

Homology and similarity between sequences were compared using the GAP and OLDDISTANCES programs in the GCG software package (version 9.1; Genetic Computer Group, Inc., Madison, WI). Multiple alignments were obtained using Clustal W (27). Phylogenetic analyses were performed using the following programs of the PHYLIP 3.5c package (J. Felsenstein, University of Washington, Seattle): DNADIST and PROTPARS to calculate genetic distances, NEIGHBOR (unweighted pair group method with arithmetic means) to cluster the variants from the distance data, and SEQBOOT (100 repetitions) and CONSENSE to perform bootstrap analyses. The TREEV 32 program was used to draw the resulting phylogenetic trees, in which apple mosaic virus served as the outgroup.

TABLE 1. Listing and properties of Prunus necrotic ringspot virus (PNRSV) isolates characterized in this study

\begin{tabular}{|c|c|c|c|c|c|c|c|}
\hline Isolate & Source $^{\mathrm{a}}$ & Symptomatology ${ }^{b}$ & Restrictotype $^{\mathrm{c}}$ & Origin & Sequence $\operatorname{code}^{\mathrm{d}}$ & Size RNA 4 nt/aa & Accession no. \\
\hline A3430 & Apricot cv. Cafona & Line pattern, necrosis & EI, RI, TI & Italy & AprIt.caf 1 & $884 / 224$ & AJ133199 \\
\hline A9170 & Apricot cv. Napoletana & Asymptomatic & EI, RI, TI & Italy & AprIt.nap 1 & $883 / 224$ & AJ133200 \\
\hline A8360 & Apricot cv.Tirynthos & Line pattern, necrosis & EI, RII, TII & Italy & AprIt.try 1 & $890 / 226$ & AJ133201 \\
\hline A6430 & Apricot cv. Errani & Severe necrotic line pattern & EI, RII, TII & Italy & $\ldots$ & $\ldots$ & $\ldots$ \\
\hline A1400 & Apricot cv. Ninfa & Line pattern & EI, RII, TII & Italy & $\ldots$ & $\ldots$ & $\ldots$ \\
\hline A8380 & Apricot cv. Boccuccia & Latent & EI, RI, TI & Italy & $\ldots$ & $\ldots$ & $\ldots$ \\
\hline M3450 & Almond cv. Tardy non Pareil & Shot hole & EI, RVI, TI & Italy & $\ldots$ & $\ldots$ & $\ldots$ \\
\hline M7960 & Almond cv. Preani & Shot hole & EI, RI, TI & Italy & AlmIt.pre1 & $884 / 224$ & AJ133202 \\
\hline M8610 & Almond cv. Core & Latent & EI, RI, TII & Italy & AlmIt.cor 1 & $884 / 224$ & AJ133204 \\
\hline M8520 & Almond cv. Oliena & Latent & EI, RI, TI & Italy & $\ldots$ & $\ldots$ & $\ldots$ \\
\hline P1000 & Peach cv. Fantasia & Yellowing, rolling of leaves & EI, RI, TI & Italy & $\ldots$ & $\ldots$ & $\ldots$ \\
\hline P8450 & Peach cv. May Crest & Latent & EI, RI, TI & Italy & PchIt.may 1 & $884 / 224$ & AJ133205 \\
\hline P2000 & Peach cv. Early Crest & Latent & EI, RI, TI & Italy & $\ldots$ & $\ldots$ & $\ldots$ \\
\hline Tunez-111 & Peach cv. unknown & Few chlorotic spots & EI, RIII, TII & Tunisia & PchTu.unk 1 & $890 / 226$ & AJ133206 \\
\hline P4090 & $\underline{\text { Peach cv. Marylin }}$ & Latent & EII, RV, TV & Italy & PchIt.mry 1 & $880 / 224$ & AJ133207 \\
\hline P4890 & Peach cv. Psa5 & Latent & EI, RII, TIV & Italy & $\ldots$ & $\ldots$ & $\ldots$ \\
\hline NcM1 & Nectarine (Murcia) & Few chlorotic spots & EI, RI, TIII & Spain & NctSp.mur 1 & $884 / 224$ & AJ133208 \\
\hline C8220 & Cherry cv. Lambert & Latent & EI, RI, TI & Italy & ChrIt.lam 1 & $884 / 224$ & AJ133203 \\
\hline C8320 & Cherry cv. Marasca & Latent & EI, RII, TIV & Italy & ChrIt.mrs 1 & $884 / 224$ & AJ133209 \\
\hline C7140 & Cherry cv. Black Giant & Some years yellowing & EII, RIV, TV & Italy & ChrIt.bla 1 & $880 / 224$ & AJ133210 \\
\hline PL11 & $\underline{\text { Plum cv. unknown }}$ & Chlorotic pattern & EI, RII, TII & Albania & PlmAl.unk 1 & $890 / 226$ & AJ133211 \\
\hline S6340 & Plum cv. C. Lopez & Asymptomatic & EI, RI, TI & Italy & PlmIt.clf 1 & $884 / 224$ & AJ133212 \\
\hline S5281 & Plum cv. unknown & Chlorotic pattern & EI, RI, TI & Italy & $\ldots$ & $\cdots$ & $\cdots$ \\
\hline S9090 & Plum cv. Stanley & Latent & EI, RII, TII & Italy & $\ldots$ & $\ldots$ & $\ldots$ \\
\hline S9040 & $\underline{\text { Plum cv. Mirabolan }}$ & Latent & EI, RII, TII & Italy & PlmIt.mrb 1 & $890 / 226$ & AJ133213 \\
\hline
\end{tabular}

a The 15 isolates representing the three main clusters of PNRSV isolates obtained by restriction fragment length polymorphism analysis are underlined.

b Observed in the natural host over several years.

c Restrictotypes determined after digestion with EcoRI, TaqI, or RsaI.

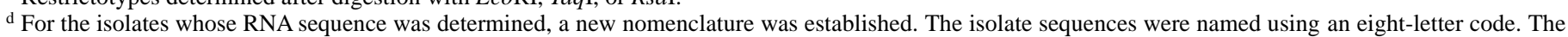
first three letters correspond to the source of the isolate, followed by two letters indicative of the country, and the last three letters indicating the cultivar. 


\section{RESULTS AND DISCUSSION}

RFLP analysis of PNRSV isolates. To obtain preliminary evidence concerning their molecular diversity, 25 PNRSV isolates from six different Prunus hosts (apricot, plum, peach, cherry, almond, and nectarine) were chosen for strain discrimination by RT-PCRRFLP analysis (Table 1). Primers VP56 and VP33, which are located at the beginning and end, respectively, of PNRSV RNA 4, were used in initial attempts to obtain full-length RNA 4 amplicons (Fig. 1A). No PCR products were obtained with isolates P4090 and C7140; therefore, the primer VPC was used instead of VP56 as the sense primer (located at the beginning of the $\mathrm{CP}$ cistron), thus providing amplification products consisting of the complete $\mathrm{CP}$ cistron and the $3^{\prime}$ untranslated region (UTR) for all isolates. RTPCR products of the expected size ( 843 to 850 base pairs [bp]) were digested with three different restriction enzymes (EcoRI, RsaI, and $T a q \mathrm{I})$. Restriction products from representative isolates, and maps based on these data are shown in Figure 1B and C, respectively. EcoRI separated the isolates into two groups (EI and EII). Group EII contained isolates P4090 and C7140, each with an identical pattern to the American isolate PE5, whereas group EI contained the rest of the isolates (Fig. 1B and C, Table 1). Group EI could be subdivided into four new groups when digested with TaqI (TI, TII, TIII, and TIV), whereas members of the EII group were included in a separate TV group. The TI and TII groups had the same restriction pattern, except that the 139-bp band of the 152/139-bp doublet in TII had a slightly lower electrophoretic mobility than the corresponding band in the isolates of the TI group, leading to the disappearance of this doublet (Fig. 1B, cf. lanes 1 and 2, TaqI gel). Sequence determination of some isolates of these two groups revealed a six-nt insertion that could explain this different electrophoretic mobility (described below). The two members of the TV

A

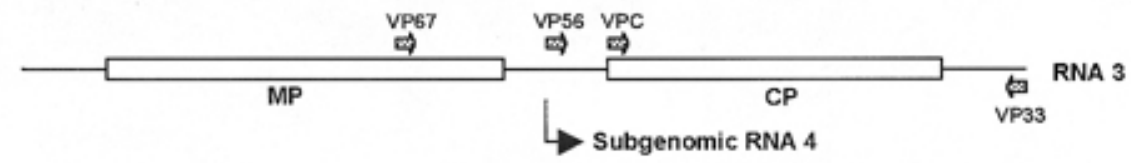

B
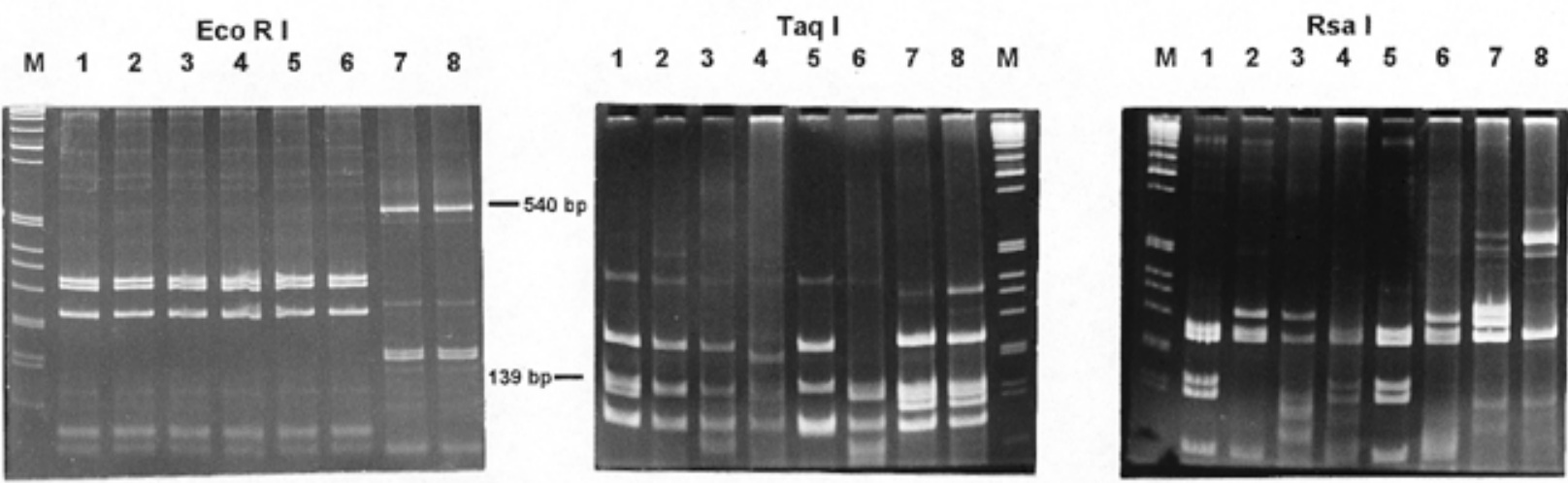

C

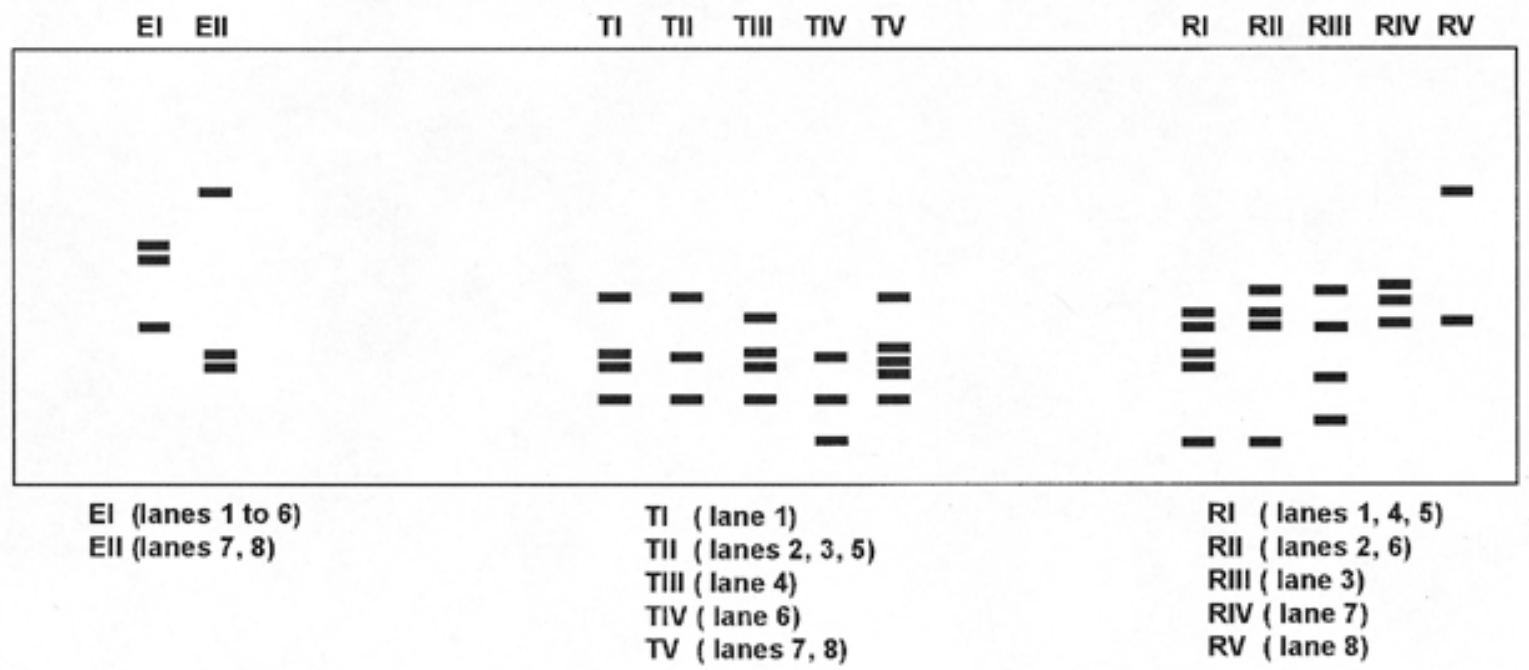

Fig. 1. A, Schematic diagram of Prunus necrotic ringspot virus (PNRSV) RNA 3 showing the location of primers used for restriction fragment length polymorphism (RFLP) analyses and for cloning and sequencing of the PNRSV isolates. B, RFLPs of reverse-transcriptase polymerase chain reaction products from eight representative PNRSV isolates: lane 1, isolate A3430; lane 2, A8360; lane 3, Tunez-111; lane 4, NcM1; lane 5, M8610; lane 6, C8320; lane 7, C7140; lane 8, P4090; and lane M, molecular weight markers (1-kilobase ladder; Gibco BRL, Bethesda, MD). C, Schematic diagram representing the fragment patterns for each restriction enzyme used. Each pattern is named with its corresponding endonuclease initial followed by a number. 
group (or EII) could only be discriminated when the RsaI restriction enzyme was used, providing the RIV and RV patterns, respectively. RFLPs RI and RII obtained with this enzyme were very similar to those of the TI and TII groups (Table 1), except that isolate Tunez-
111 , belonging to the TII group, possessed a unique $R s a$ I restrictotype (Fig. 1B, RIII, RsaI gel, lane 3). By scoring the presence or absence ( 1 or 0 , respectively) of each restriction fragment in all the isolates, a matrix was generated that allowed calculation of the ge-
PV96

PlmIt.clf 1 PehIt may 1 Aprit. nap NetSp. mur AlmIt.cor 1 AlmIt pre AprIt.caf 1 ChrIt.mrs ChrIt. Iam1

PV32

PlmA1.abn 1

AprIt. try 1

PImIt.mrb PchTu . tun 1

PE5

ChrIt.bla1 PchIt.mry1

PV96

PlmIt.clf1

PchIt.mayl AprIt.nap 1 NetSp.mur1 AlmIt.cor AlmIt.pre 1 AprIt.caf 1 ChrIt.mrs 1 ChrIt. lam.

PV32

PlmAl abn I AprIt . try 1 PlmIt. mrb1 PchTu. tun1

PE5

ChrIt.bla1 PchIt.mry 1

\section{PV96}

PlmIt.c1 1

AprIt.nap1

Aprit.nap1

NetSp.mur1

AlmIt.prel

AlmIt.pre1

AprIt.caf1

ChrIt. Iam1

PV32

PlmA1.abn1 AprIt try 1 PchTu.tun1

PE5

ChrIt.bla1 PchIt.mryl

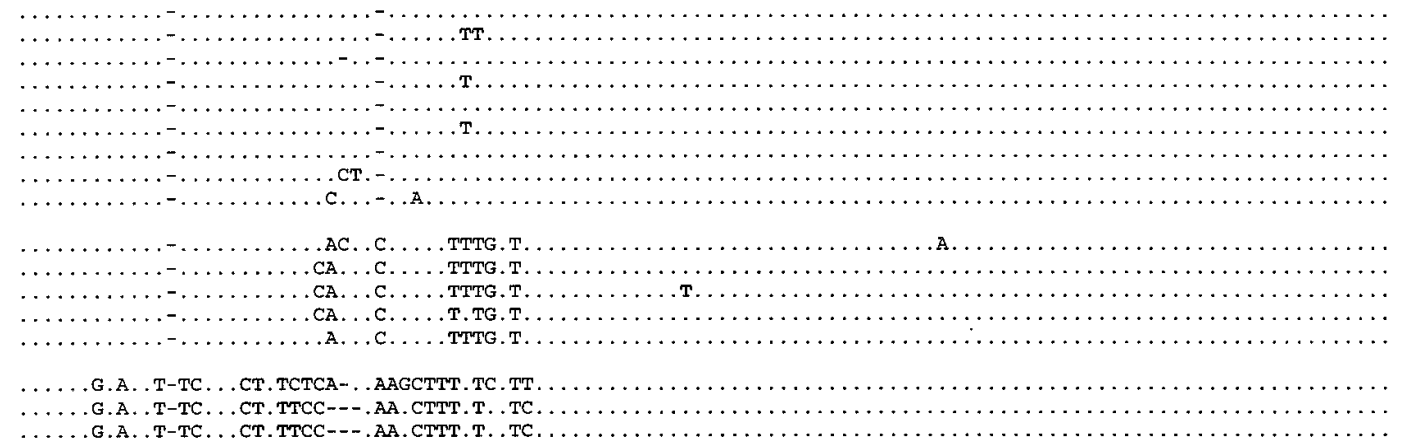

111

216

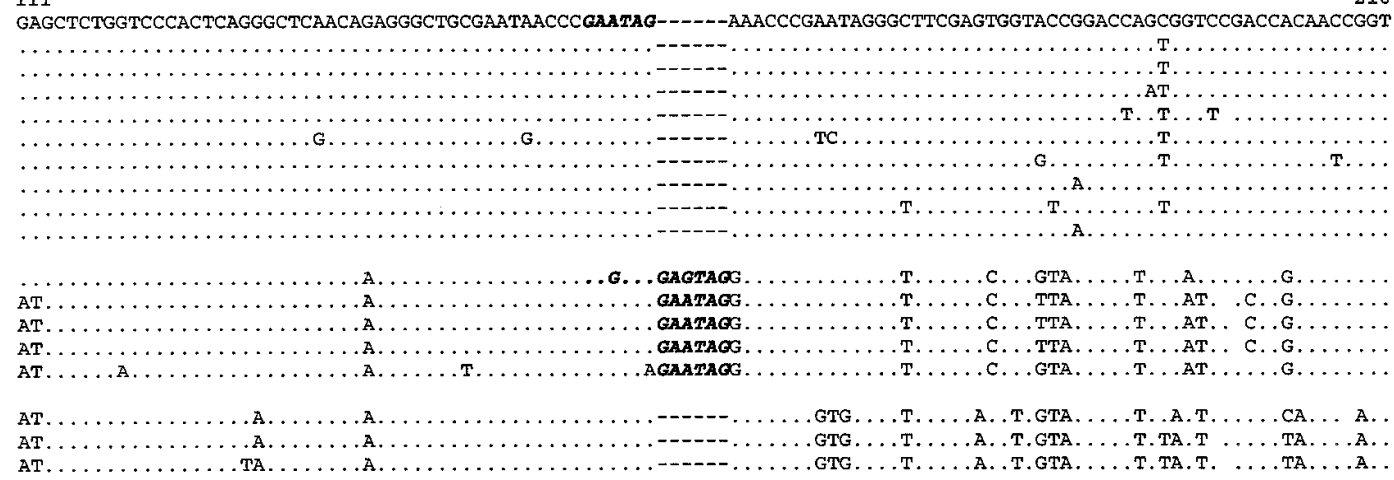

21

CGTGAAGACCACCTGGACCGTGAGAGGTCCGAATGTGCCTCCCCGAATTCCTAAGGGGTTTGTAGCACACAATCACCGAGAGGTGACGACGACAGAGGCAGTGAAG 328

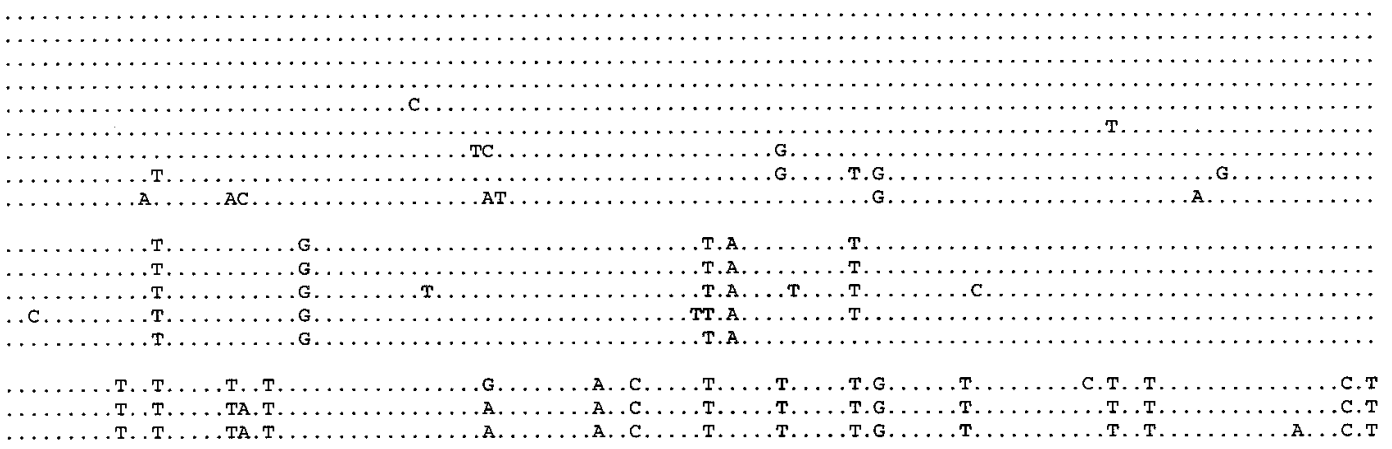

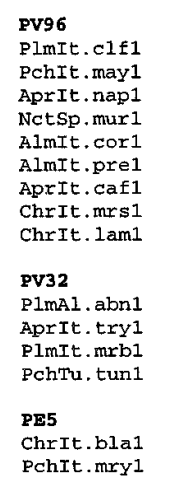

AGCATAGACTTCACGACCACTCTCCCTCAGTTGATGGGTCAGAATTTGACCCTATTGACIGTTATAGTCCGAATGAACTCTATGAGTTCGAATGGTTGGATTGGGATGGTGG

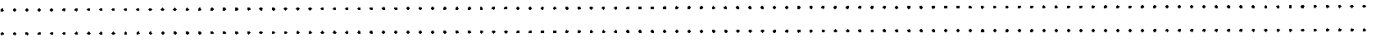

.T

$\ldots$ T.
T. . .
T.
T.
T.
T.
т.
т.

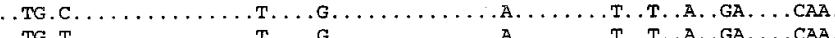

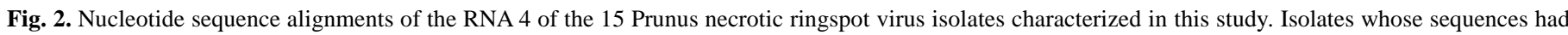

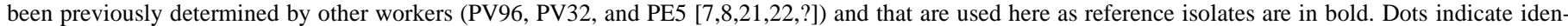
tical residues. Dashes denote gaps in the sequence. The extra hexanucleotide present in the PV32 subgroup is marked in bold. The start codon is underlined. 
netic distances and the corresponding dendrogram (data not shown). Three main clusters of PNRSV isolates were obtained and 15 isolates representing the three different groups obtained by RFLP analysis were chosen for further characterization (Table 1, underlined).
Sequences and comparative analysis of the RNA 4. Full-length RNA 4 amplified by using primers VP56 and VP33 (Fig. 1A) was obtained from the 15 isolates mentioned above. The corresponding PCR fragments were excised from agarose gels and, after diges-

Fig. 2. (continued from preceding page)

PV96

PlmIt.clf1

PchIt . may 1

AprIt.nap1

Natsp mur1

NCtSp. mur

AlmIt.cor

AlmIt.pre1

AprIt.caf1

ChrIt . lam1

Pv32

P1mA 1 abn1

AprIt.try 1

PlmIt.mrb1

PchTu, tun1

PF5

ChrIt.bla1

PehIt.mry 1

PV96

PlmIt. clf1

PehIt may 1

AprIt. nap1

NetSp.mur1

NetSp.mur

AlmIt.cor 1

AprIt. caf

ChrIt.mrs 1

PV32

P1mA1 abn1

AprIt . try

PlmIt.mrb1

PchTu. tun

PE5

ChrIt.blal

PchIt.mry1

PV96

PlmIt.clf

PchIt.may 1

AprIt. nap

NctSp.mur 1

AlmIt cor 1

AlmIt,cor

AlmIt.pre

AprIt.caf

ChrIt. I am

Pv32

Plmal. abn 1

AprIt.try

PlmIt.mrb

PchTu . tun

PE5

ChrIt.blal

PchIt.mry1

PV96

P1mIt. clf1

PchIt.may

AprIt. nap1

NctSp.mur

AlmIt cor

Almit.cor

AlmIt.pre

AprIt.caf

ChrIt. lam1

PV32

PlmAl . abn 1

AprIt.try

plmIt. mrb

PchTu.tun1

PE5

ChrIt.blaI

PehIt.mryl
441

552

AGGACTATAAGGTGGAACGACCTGATGGTCCGAATGCCCTGTCTAGGAAGGGGTTCTTGAAGGACCAACCGAGAGGTTGGCAGTTCGAACCTCCTTCCGATTTAGATTTCGA

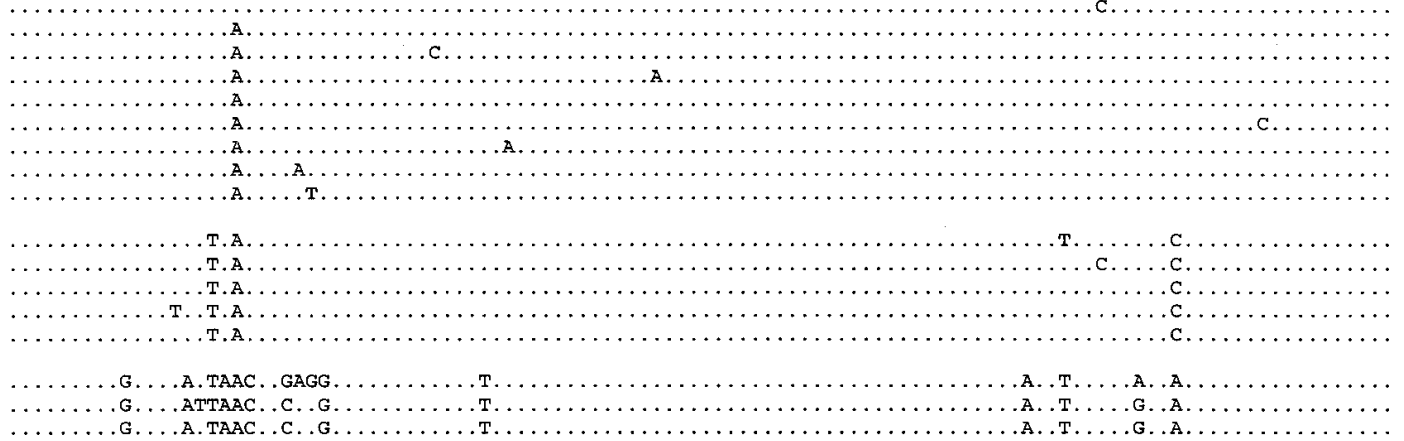

553

A.T. T G A

CACTTTTGCGCGTACGCATCGTGTCGTTATCGAATTCAAGACCGAAGTGCCCGCTGGGCCAAGGTCTTGGTTAGGGATTTGTACGTAGTGGTAAGTGATTIACCACGAG

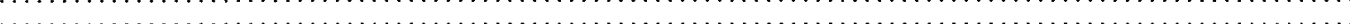

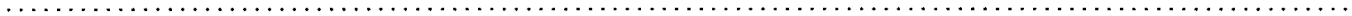

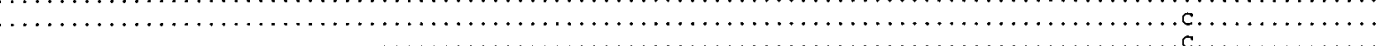

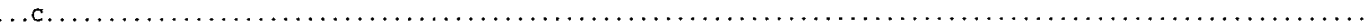

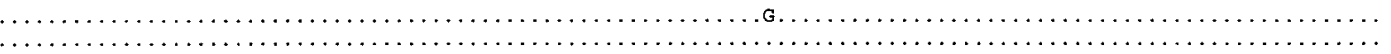

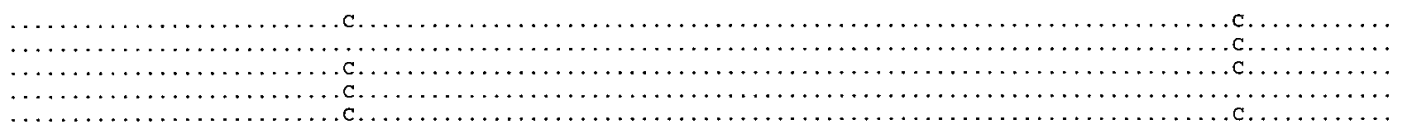

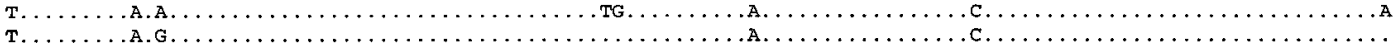

т.

$665 \quad \mathbf{7 7 6}$

CAAATTCCGACTGATGTCTTGCTGGTCGATGAAGACCTGCTTGAGATCTAGAGTGAGATAAGCACACTCGAATTTTCTCCGAATGGAAAGTTCGCACCACCGATAGTGGATA A.





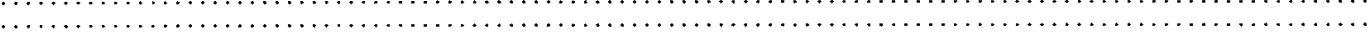

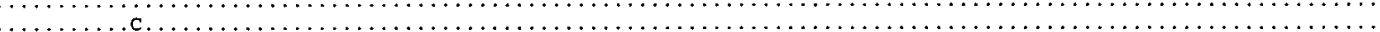

(.......

.

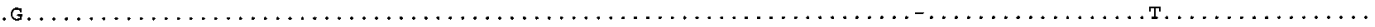

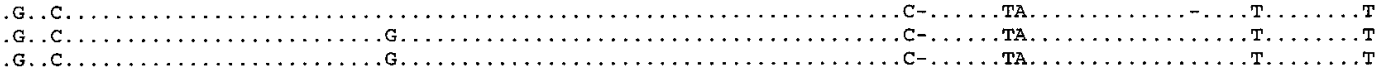

777 884

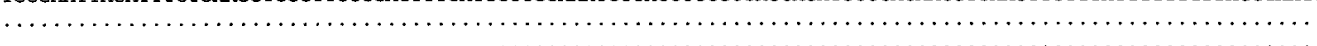



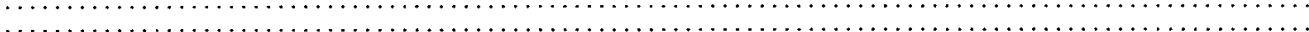

с....

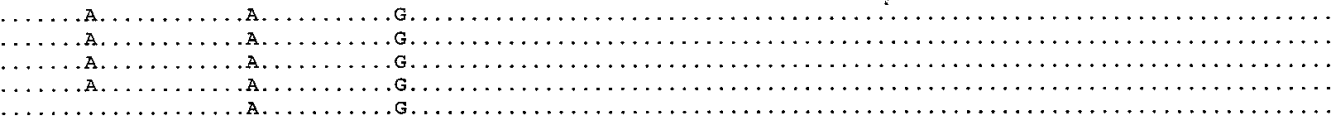

С............ . . А. Т......... СТT .

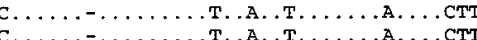


tion with appropriate restriction enzymes, were cloned into the plasmid vector pUC18. For two isolates, the complete nucleotide sequence of three different clones was established and no heterogeneity was found. It was decided to then select single clones from the rest of the isolates for nucleotide sequencing. RNA 4 sequences were aligned (Fig. 2) and the corresponding phylogenetic tree was generated (Fig. 3A). Three different groups, represented by the first three PNRSV isolates characterized (PV32, PV96, and PE5) (Table 2) $(7,8,21,22)$, were clearly differentiated. The size of the RNA 4 of the different isolates ranged from 880 to $890 \mathrm{nt}$, with $884 \mathrm{nt}$ being the most frequent size ( 8 out of 15 isolates), whereas the size of the CP was either 224 or 226 amino acids (aa). Initial visual inspection of the alignment revealed that most of the variability was concentrated in the first third of the molecule (nt 1 to 350). The intragroup percentage of identity was 94.8 to $99.5 \%$ for the PV96-type group, 97.9 to $99.2 \%$ for the PV32 group, and 96.8 to $99.8 \%$ for the PE5 group. The 5' UTR sequences belonging to the PE5-type were clearly different from those of the other two groups, a fact that is consistent with the inability of primer VP56 to amplify these isolates (described above). Isolates from the PV32-type group were characterized by having an extra hexanucleotide consisting of a direct repeat of the immediately preceding six nt. When the secondary structure around this hexanucleotide was examined in isolates with no duplication (Fig. 4, representative isolate

TABLE 2. Listing of Prunus necrotic ringspot virus isolates previously characterized and used as references in this study

\begin{tabular}{llcl}
\hline Isolate & \multicolumn{1}{c}{ Origin } & References & Accession no. \\
\hline PE5, Prunus persica L. Batsch & United States & 8 & L38823 \\
PV96, Prunus mahaleb L. & Germany & 7 & S78312 \\
PV32, Malus spp. & United States & 21,22 & U03857, Y07568 \\
ApMVa, Malus spp. & United States & 26 & U15608 \\
\hline
\end{tabular}

a Apple mosaic virus.
A

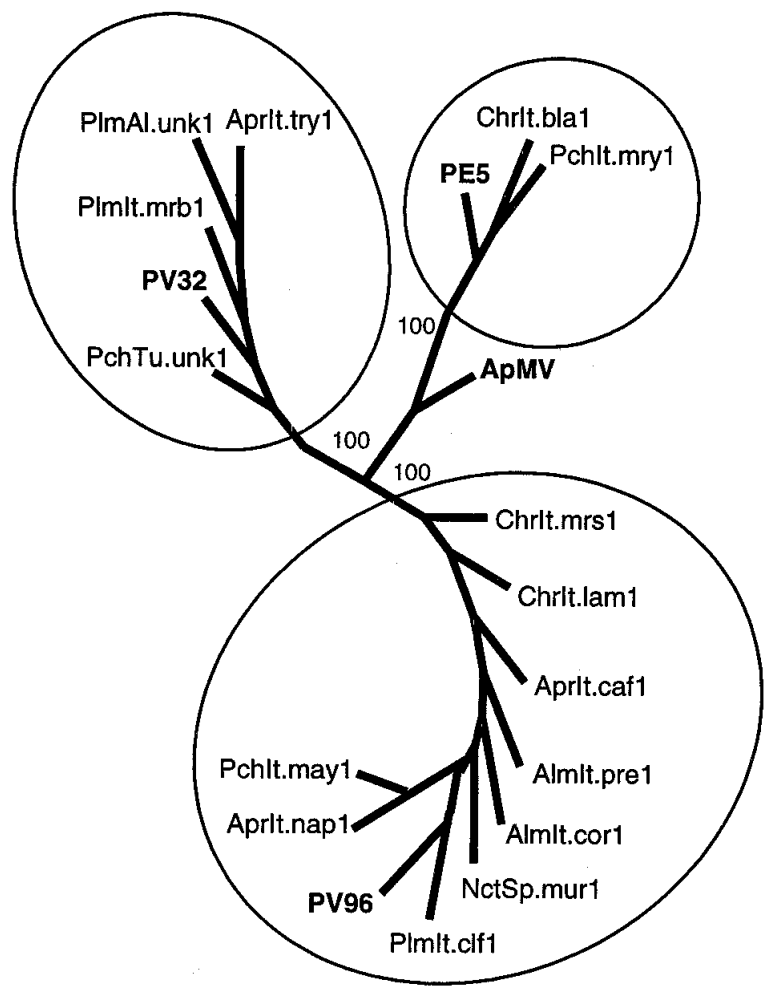

B

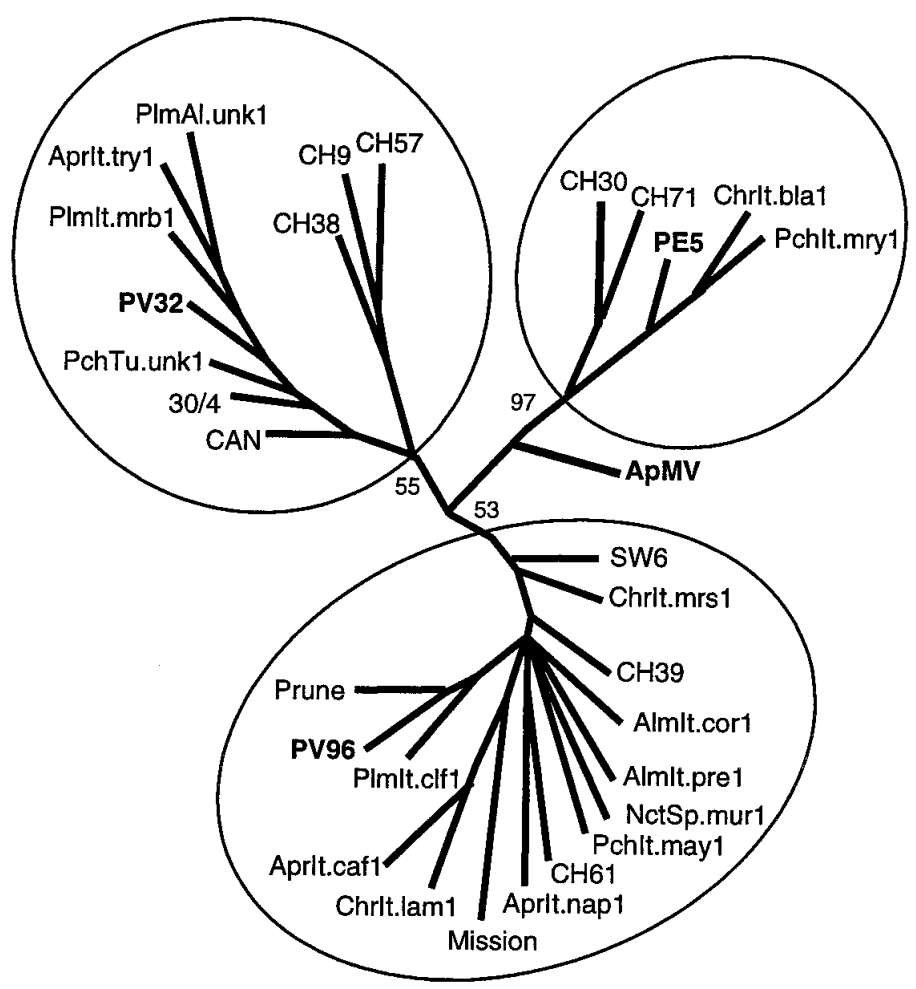

Fig. 3. Phylogenetic trees of the A, nucleotide and $\mathbf{B}$, amino acid sequences of the Prunus necrotic ringspot virus (PNRSV) RNA 4 isolates characterized in this study. Phylogenetic analysis was based on genetic distances (PHYLIP 3.5c package). The numbers near nodes were determined by bootstrap analysis (100 replicates). The PNRSV sequences reported previously are indicated in bold. Amino acid sequences characterized by Scott et al. (25) and Hammond and Crosslin (9) have also been included in $\mathbf{B}$.

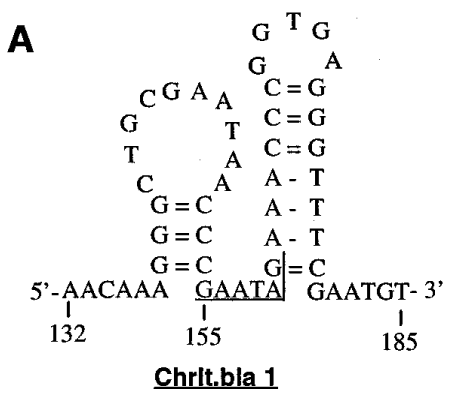

$\mathbf{B}$

$\mathrm{G}_{\mathrm{C}=\mathrm{G}}^{\mathrm{A}}$
$\mathrm{C}=\mathrm{G}$
$\mathrm{C}=\mathrm{G}$
$\mathrm{A}-\mathrm{T}$
$\mathrm{A}-\mathrm{T}$
$\mathrm{G}-\mathrm{T}$
$\mathrm{G}=\mathrm{C}$

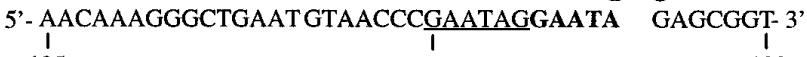

135

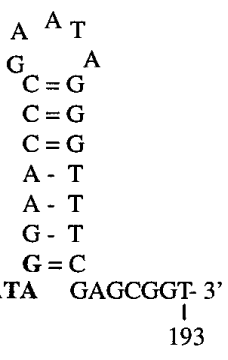

PImAl.unk 1

Fig. 4. Secondary structure proposed for A, Prunus necrotic ringspot virus isolates lacking the hexanucleotide repeat, represented by sequence ChrIt.bla1, and for $\mathbf{B}$, isolates bearing this repeat, represented by PlmAl.unk1. Secondary structures were generated by using the RNA fold program. Models proposed for the generation of these repeats are described in text. 
ChrIt.bla1), it was noted that the hexanucleotide to be duplicated immediately preceded a very stable stem-loop structure (G-C pairs in three out of six positions in the stem). The duplication could then be explained by assuming an intramolecular rearrangement due to a "jumping” RNA polymerase in discontinuous transcription, following the replicative template switch model previously proposed in other systems $(1,10)$. The presence of the duplicate hexanucleotide in the PV32-type isolates produced two extra amino acids (NR [Asp-Arg] in all of them except in the case of PV32, in which there was an SR [Ser-Arg] insert) in their CPs (Fig. 5). This duplication has been observed in four different hosts (plum, apricot, and peach in this work and Scott et al. [25]; and in cherry $[9,25])$, in-
PV96

PlmIt.clf1

PchIt.may 1

AprIt.napl

NctSp.mur 1

AlmIt.cor1

AlmIt.pre1

AprIt.caf1

ChrIt.mrs1

ChrIt. Iam1

PV32

PlmA1.unk1

AprIt . try1

PlmIt.mrb1

PchTu . unk1

PE5

ChrIt.bla1

pchIt.mry1 MVCRICNHTHAGGCRSCKKCHPNGALVPLRAQQRAANNPNR- -NPNRASSGTGPAVRPQPVVKTTWTVRGPNVPPR

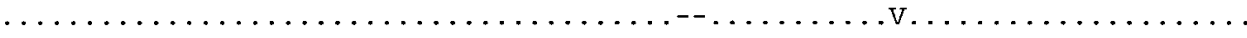

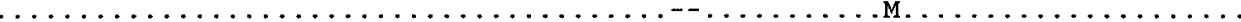

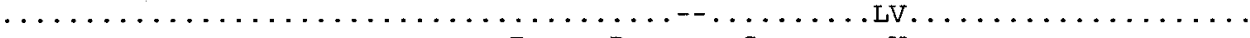

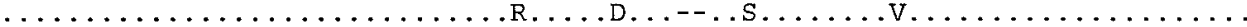

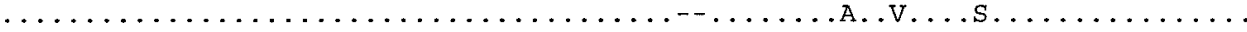

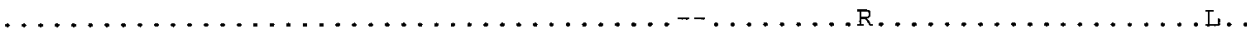

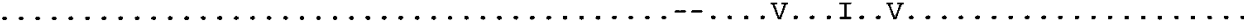

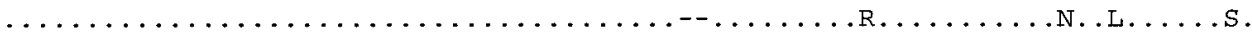

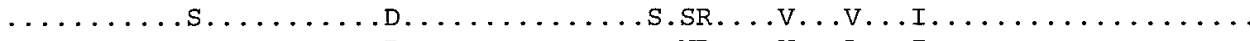

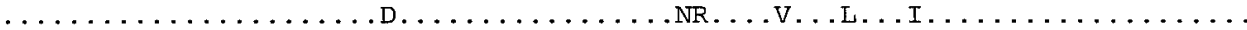

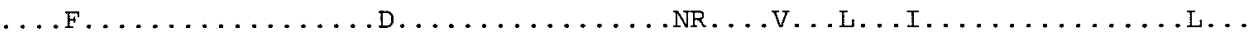

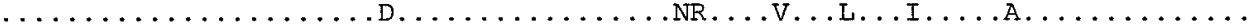

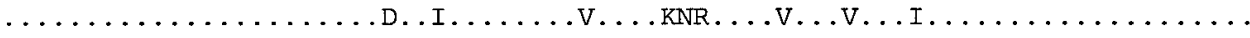

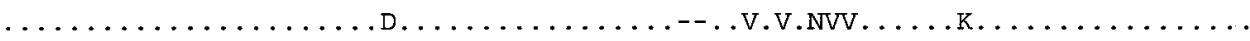

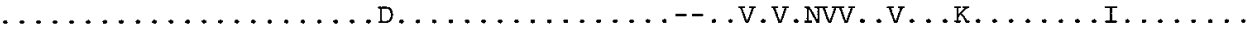

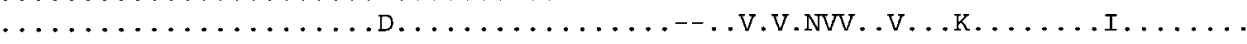

PV96

PlmIt.clf1 IPKGFVAHNHREVTTTEAVKYLSIDFTTTLPQLMGQNLTLLTVIVRMNSMSSNGWIGMVEDYKVERPDGPNALSRK

PchIt.may1 AprIt . nap1 NctSp.mur 1 AlmIt.cor 1 AlmIt.pre1 AprIt.caf1 ChrIt.mrs 1 ChrIt. I aml

PV32

PlmA I . unk1 AprIt . try1 PlmIt.mrb1 PchTu. unk1

PE5

ChrIt.bla1 pchIt.mryl

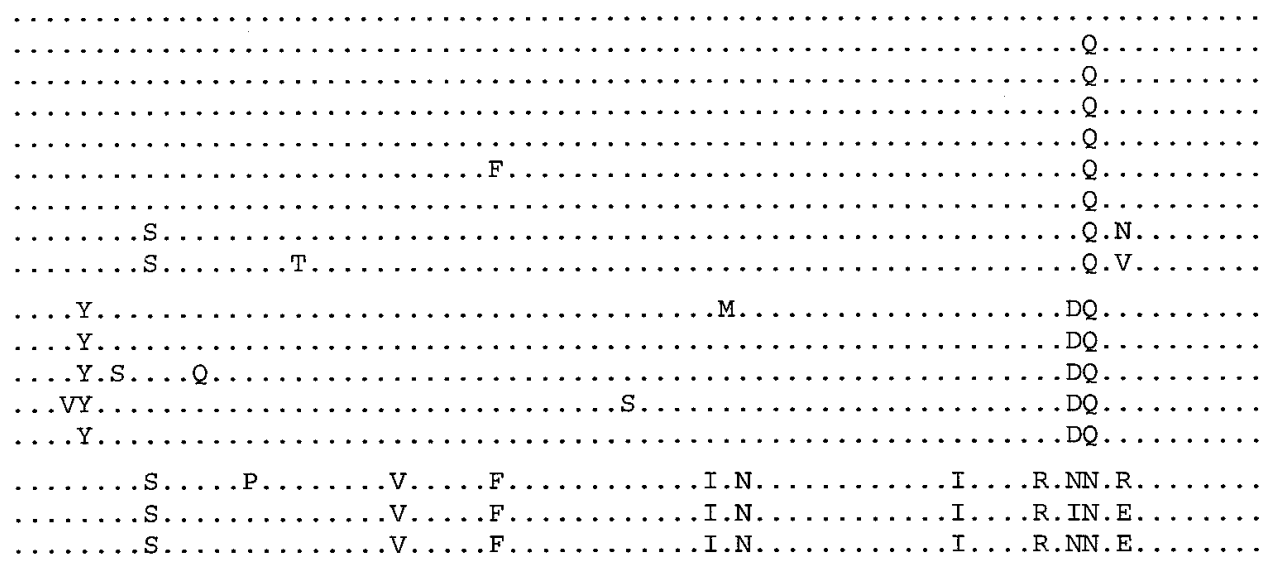

151

224

PV96

PlmIt. clf 1

PchIt.may1

AprIt.napl

NetSp.mur1

AlmIt.cor 1

AlmIt.prel

AprIt.caf1

ChrIt.mrs1

ChrIt. Iam1

GFLKDQPRGWQFEPPSDLDFDTFARTHRVIEFKTEVPAGAKVLVRDLYVVVSDLPRVQIPTDVLLVDEDLLEI

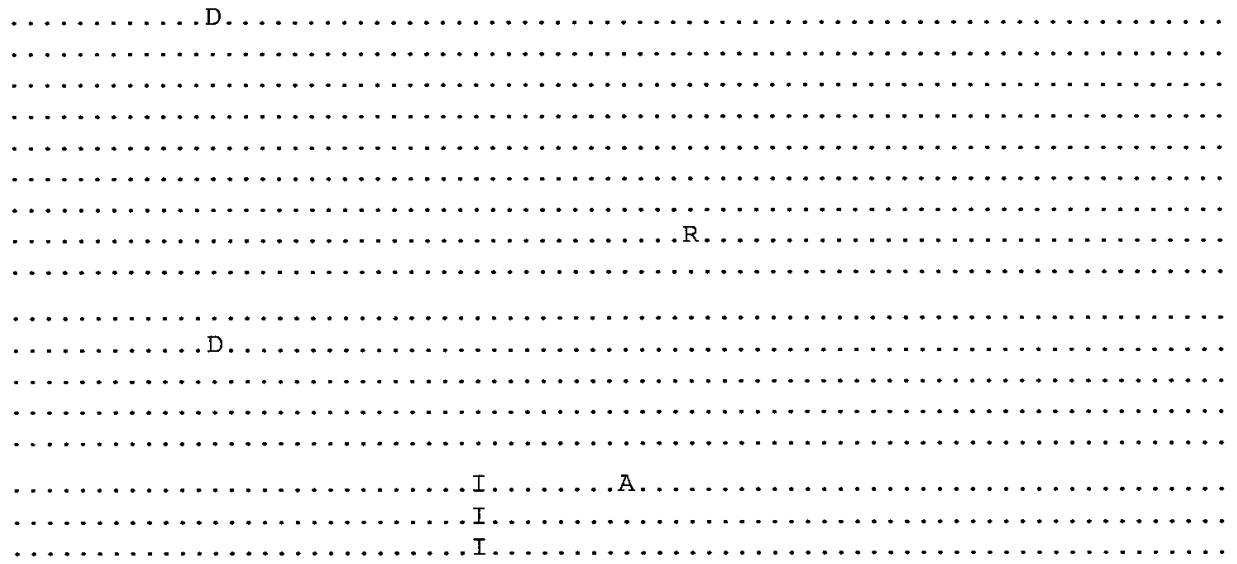

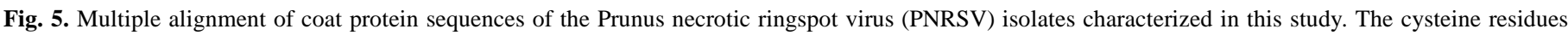

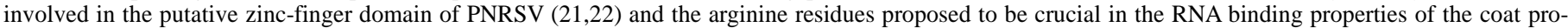
tein (2) are marked in bold. Note the two extra amino acids present in members of the PV 32 group. 
dicating that it is not the result of host selection or the adaptation of PNRSV sequence variations.

Sequences and comparative analysis of the CPs. The N-terminus and the C-terminus of the protein were both extremely well conserved with most of the variability at the amino acid level occurring between positions 41 and 58 (Fig. 5). At the N-terminus, the four Cys residues involved in the putative zinc-finger motif previously proposed for PNRSV $(16,21)$ are strictly conserved, as is the arginine residue, which by analogy with AMV, tobacco streak virus, and citrus leaf rugose virus, is involved in the RNA binding properties of the CP (2). Recently, Hammond and Crosslin (9) determined the sequence of the RNA 3 of seven PNRSV isolates that differed in serological relationships and pathology in sweet cherry. They proposed that limited changes at the amino acid level in the CP correlated well with symptom types (pathotypes) in cherry and identified four amino acid substitutions in the isolates causing rugose mosaic. Special attention was paid to the T50-I and F79-Y substitutions. Only one isolate (ChrIt.mrs1) of those sequenced in the current work possessed the T50-I substitution, although it is considered to be a latent isolate (Table 1). More interesting is the fact that the F79-Y substitution was present in all four isolates of the PV32-type group, three of which cause some kind of chlorotic or necrotic syndrome. However, the fact that some isolates that induce a similar symptomatology (e.g., AprIt.caf1) lack the aforementioned amino acid substitution indicates that the correlation observed for cherry isolates is not necessarily valid for other hosts.

The phylogenetic tree generated from the amino acid sequence data showed essentially the same three groups as described above (Fig. 3B). When the cherry isolates characterized by Hammond and Crosslin (9) were included in this phylogenetic study, isolates of the $\mathrm{CH} 30$ serotype $(\mathrm{CH} 30$ and $\mathrm{CH} 71)$ clustered in the PE5-type group, as previously noted. Interestingly, mild isolates of the $\mathrm{CH} 9$ serotype (CH61 and $\mathrm{CH} 39$ ) clustered in the PV96type group, whereas rugose isolates of the $\mathrm{CH} 9$ serotype $(\mathrm{CH} 38$, $\mathrm{CH} 59$, and $\mathrm{CH} 9$ ) clustered in a subgroup within the PV32-type group. On the other hand, isolates 30/4 and CAN, recently described by Scott et al. (25) and which both have the two extra aa, clustered within the PV32-type group, as expected, whereas isolates Prune, Mission, and SW6 fell within the PV96-type group (Fig. 3B), thus validating the universality of the grouping proposed in this work.

It is worth noting that both the $\mathrm{N}$-terminus and the C-terminus of the CP are extremely well conserved and show almost no variability. The CP of PNRSV and of Ilarvirus spp. in general has a very different charge distribution at both ends of the molecule, the $\mathrm{N}$-terminus being very basic ( $\mathrm{pI}>13$ at $\mathrm{pH}$ 7) and the C-terminus extremely acidic ( $\mathrm{pI}<4.3$ at $\mathrm{pH} 7$ ). Taking into consideration this asymmetry and previous experimental evidence, we previously proposed a model for the initiation of infection in which the Ilarvirus sp. CP would act as the transactivating domain of many transcription factors (21): the N-terminal region of the $\mathrm{CP}$ could bind to the 3 ' terminal region of the RNA and the acidic C-terminal domain could interact with a replicase complex to facilitate its contact with the genomic RNA. This model was extended by HouserScott et al. (11) to accommodate the 3' terminal nucleotide in the correct orientation for the accurate initiation of replication (4). The high degree of conservation of the $\mathrm{N}$ - and $\mathrm{C}$-terminus ends shown by the CPs of the isolates sequenced in this work is consistent with this model.

\section{ACKNOWLEDGMENTS}

Grant BIO96-0459 from the Spanish granting agency DGICYT supported this work. F. Aparicio was the recipient of a fellowship of the Ministerrio de Educación y Cultura of Spain. We thank J. A. SánchezNavarro for his valuable comments during this work and P. Thomas for the English version of the manuscript.

\section{LITERATURE CITED}

1. Agol, I. V. 1997. Recombination and other genomic rearrangements in Picornaviruses. Virology 8:77-84.

2. Ansel-Mckinney, P., Scott, S. W., Swanson, M., Ge, X., and Gehrke, L. 1996. A plant viral coat protein RNA binding consensus sequence contains a crucial arginine. EMBO (Eur. Mol. Biol. Organ.) J. 15:50775084.

3. Barbara, D. J., Clark, M. F., Thresh, J. M., and Casper, R. 1978. Rapid detection and serotyping of Prunus necrotic ringspot virus in perennial crops by enzyme-linked immunosorbent assay. Ann. Appl. Biol. 90:395399.

4. Bol., J. F. 1999. Alfalfa mosaic virus and ilarviruses: Involvement of coat protein in multiple steps of the replication cycle. J. Gen. Virol. 80: 1089-1102.

5. Crosslin, J. M., and Mink, G. I. 1992. Biophysical differences among Prunus necrotic ringspot ilarviruses. Phytopathology 82:200-206.

6. Felsenstein, J. 1989. Phylip-Phylogeny Inference Package (version 3.2). Cladistic 5:164-166

7. Guo, D., Maiss, E., Adam, G., and Casper, R. 1995. Prunus necrotic ringspot ilarvirus: Nucleotide sequence of RNA 3 and the relationship to other ilarviruses based on coat protein comparison. J. Gen. Virol. 76: 1073-1079.

8. Hammond, R. W., and Crosslin, J. M. 1995. The complete nucleotide sequence of RNA 3 of a peach isolate of Prunus necrotic ringspot virus. Virology 208:349-353.

9. Hammond, R. W., and Crosslin, J. M. 1998. Virulence and molecular polymorphism of Prunus necrotic ringspot virus isolates. J. Gen. Virol. 79:1815-1823.

10. Hataya, T., Nakahara, K., Ohara, T., Ieki, H., and Kano, T. 1998. Citrus viroid Ia is a derivate of citrus bent leaf viroid (CVd-Ib) by partial sequence duplications in the right terminal region. Arch. Virol. 143:971980 .

11. Houser-Scott, F., Ansel-McKinney, P., Cai, J. M., and Gehrke, L. 1997. In vitro genetic selection analysis of alfalfa mosaic virus coat protein binding to 3'-terminal AUGC repeats in the viral RNAs. J. Virol. 71: 2310-2319.

12. Howell, W. E., and Mink, G. I. 1988. Natural spread of cherry rugose mosaic disease and two Prunus necrotic ringspot virus biotypes in a central Washington sweet cherry orchard. Plant Dis. 72:636-640.

13. Mink, G. I., Howell, W. E., Cole, A., and Regev, S. 1987. Three serotypes of Prunus necrotic ringspot virus isolated from rugose mosaic-disease sweet cherry trees in Washington. Plant Dis. 68:207-210.

14. Neeleman, L., Van der Kuyl, A. C., and Bol, J. F. 1991. Role of alfalfa mosaic virus coat protein gene in symptom formation. Virology 181: 687-693.

15. Pallás, V., Más, P., and Sánchez-Navarro, J. A. 1998. Detection of plant RNA viruses by non-isotopic dot-blot hybridization. Pages 461-468 in: Plant Virus Protocols: From Virus Isolation to Transgenic Resistance. G. Foster and S. Taylor, eds. Humana Press, Totowa, NJ.

16. Pallás, V., Sánchez-Navarro, J. A., and Díez, J. 1999. In vitro evidence for RNA binding properties of the coat protein of Prunus necrotic ringspot ilarvirus and their comparison to related and unrelated viruses. Arch. Virol. 144:797-803.

17. Rampitsch, C., and Eastwell, K. C. 1997. The complete nucleotide sequence of prune dwarf ilarvirus RNA-1. Arch. Virol. 142:1911-1918.

18. Rosner, A., Maslenin, L., and Spiegel, S. 1998. Differentiation among isolates of Prunus necrotic ringspot virus by transcript conformation polymorphism. J. Virol. Methods 74:109-115.

19. Rybicki, E. P. 1995. Family Bromoviridae. Pages 450-457 in: Virus Taxonomy. Sixth Rep. Int. Comm. Taxon. Viruses. F. A. Murphy, C. M. Fauquet, D. H. L. Bishop, S. A. Ghabrial, A. W. Jarvis, G. P. Martelli, M. A. Mayo, and M. D. Summers, eds. Springer-Verlag Wien, New York.

20. Sánchez-Navarro, J. A., Aparicio, F., Rowhani, A., and Pallás, V. 1998. Comparative analysis of ELISA, non-radioactive molecular hybridization and PCR for the detection of Prunus necrotic ringspot virus in herbaceous and Prunus hosts. Plant Pathol. 47:780-786.

21. Sánchez-Navarro, J. A., and Pallás, V. 1994. Nucleotide sequence of apple mosaic ilarvirus RNA 4. J. Gen. Virol. 75:1441-1445.

22. Sánchez-Navarro, J. A., and Pallás, V. 1997. Evolutionary relationships in the ilarviruses: Nucleotide sequence of Prunus necrotic ringspot RNA 3. Arch. Virol. 142:749-763.

23. Sánchez-Navarro, J. A., Reusken, C. B. E. M., Bol, J. F., and Pallás, V. 1997. Replication of alfalfa mosaic virus RNA 3 with movement and coat protein genes replaced by corresponding genes of Prunus necrotic ringspot ilarvirus. J. Gen. Virol. 78:3171-3176.

24. Scott, S. W., Zimmerman, M. T., and Ge, X. 1998. The sequence of RNA 1 and RNA 2 of tobacco streak virus: Additional evidence for the inc- 
lusion of alfalfa mosaic virus in the genus Ilarvirus. Arch. Virol. 143: 1187-1198.

25. Scott, S. W., Zimmerman, M. T., Ge, X., and MacKenzie, D. J. 1998. The coat proteins and putative movement proteins of isolates of Prunus necrotic ringspot virus from different host species and geographic origins are extensively conserved. Eur. J. Plant Pathol. 104:155-161.

26. Shiel, P. J., Alrefai, R. H., Domier, L. L., Korban, S. S., and Berger, P. H. 1995. The complete nucleotide sequence of apple mosaic virus RNA 3.
Arch. Virol. 140:1247-1256.

27. Thompson, J. D., Higgins, D. G., and Gibson, T. J. 1994. CLUSTAL W: Improving the sensitivity of progressive multiple sequence alignment through sequence weighting, position-specific gap penalties and weight matrix choice. Nucleic Acids Res. 22:4673-4680.

28. Uyemoto, J. K., and Scott, S. W. 1992. Important diseases of Prunus caused by viruses and other graft-transmissible pathogens in California and South Carolina. Plant Dis. 76:5-11. 